\title{
Tropical Pacific Decadal Variability and Its Relation to Decadal Modulations of ENSO
}

\author{
KeITH B. Rodgers \\ Laboratoire d'Océanographie Dynamique et de Climatologie, Paris, France \\ PETRA FriederichS \\ Meteorologisches Institut, Bonn, Germany \\ MoJIB LATIF \\ Institut fuer Meereskunde, Kiel, Germany
}

(Manuscript received 29 January 2003, in final form 18 November 2003)

ABSTRACT

\begin{abstract}
A 1000-yr integration of a coupled ocean-atmosphere model (ECHO-G) has been analyzed to describe decadal to multidecadal variability in equatorial Pacific sea surface temperature (SST) and thermocline depth (Z20), and their relationship to decadal modulations of El Niño-Southern Oscillation (ENSO) behavior. Although the coupled model is characterized by an unrealistically regular 2-yr ENSO period, it exhibits significant modulations of ENSO amplitude on decadal to multidecadal time scales.

The authors' main finding is that the structures in SST and Z20 characteristic of tropical Pacific decadal variability (TPDV) in the model are due to an asymmetry between the anomaly patterns associated with the model's El Niño and La Niña states, with this asymmetry reflecting a nonlinearity in ENSO variability. As a result, the residual (i.e., the sum) of the composite El Niño and La Niña patterns exhibits a nonzero dipole structure across the equatorial Pacific, with positive perturbation values in the east and negative values in the west for SST and Z20. During periods when ENSO variability is strong, this difference manifests itself as a rectified change in the mean state.

For comparison, a similar analysis was applied to a gridded SST dataset spanning the period 1871-1999. The data confirms that the asymmetry between the SST anomaly patterns associated with El Niño and La Niña for the model is realistic. However, ENSO in the observations is weaker and not as regular as in the model, and thus the changes due to ENSO asymmetries for the observations can only be detected in the Niño-12 region.
\end{abstract}

\section{Introduction}

Recently, much attention has been devoted to decadal variability in the Pacific in the climate literature. Graham (1994) and Trenberth and Hurrell (1994) used historical SST observations to describe a basin-scale warming in the equatorial Pacific in 1976/77, during which basin-scale surface temperatures increased by nearly $1^{\circ} \mathrm{C}$. Applying statistical analysis to a global monthly SST dataset over 1900-92, Zhang et al. (1997) argued that the SST shift in 1976/77 represented only the most recent transition of a "mode" of climate variability that is often referred to as the Pacific decadal oscillation (PDO). The SST pattern characteristic of the PDO is basin scale for the Pacific Ocean (see Fig. 11 of Zhang et al. 1997), with temperature variations in the subtrop-

Corresponding author address: Dr. Keith B. Rodgers, Laboratoire d'Océanographie Dynamique et de Climatologie, T45-55, 4E 4 pl. Jussieu-boite 100, 75252 Paris Cedex 05, France.

E-mail: rodgers@lodyc.jussieu.fr ical gyres of the North and South Pacific in phase with each other and out of phase with the changes in the eastern and central equatorial Pacific. As such, the characteristic SST perturbation structure associated with the PDO has ENSO-like basin-scale structure (although there are some important differences in the structure of the ENSO and PDO patterns in the equatorial regions). The analysis of Zhang et al. (1997) revealed that prior to $1976 / 77$, abrupt regime shifts had occurred in the $1940 \mathrm{~s}$, as well as in the first decade of the twentieth century.

Here our primary interest is in tropical Pacific decadal variability (TPDV). There is an ongoing debate in the climate literature as to whether TPDV is generated by coupled processes within the Tropics (Knutson et al. 1997; Kirtman and Schopf 1998; Clement et al. 2001; Vimont et al. 2002; Timmermann and Jin 2002; Timmermann et al. 2003; Timmermann 2003), or whether it involves interactions with the extratropics (Latif and Barnett 1994, 1996; Barnett et al. 1999; Gu and Philander 1997; McCreary and Lu 1994; Kleeman et al. 
1999). Among those who argue for a tropically generated TPDV, there is heated debate over whether TPDV should be understood as being stochastically excited, or as being the result of nonlinearities in the coupled tropical system.

In the observations, the changes in the equatorial $\mathrm{Pa}$ cific thermocline stratification and circulation are not well constrained over decadal time scales because of the paucity of pre-1976 subsurface measurements. Such subsurface changes are of interest as it is thought that low-frequency changes in thermocline depth or thermocline stratification may provide a means to modulate the amplitude and frequency of ENSO. Of all of the sensitivity studies considered by Zebiak and Cane (1991) with their coupled model, they found that changes in El Niño frequency and amplitude are most sensitive to changes in stratification of the equatorial thermocline. However, for the modeling configuration of Zebiak and Cane the mean equatorial thermocline stratification was imposed for each experiment (Zebiak and Cane 1991), and thus it was not possible to evaluate to what extent there is any interaction between changes in El Niño behavior and changes in mean stratification for the coupled system. Timmermann et al. (1999), in their analysis of the ENSO response to greenhouse warming in a global climate model, invoked increases in equatorial Pacific stratification (their Fig. 1) to account for increases in ENSO variability under future greenhouse warming conditions.

It is also known from observations ( $\mathrm{Gu}$ and Philander 1995; Torrence and Webster 1999) that the amplitude of ENSO variability changes over decadal time scales. It is thought that the shift to warmer conditions in the equatorial Pacific in 1976/77 is associated with an increase in ENSO amplitude, although this cannot be demonstrated with statistical significance. Coupled models can therefore provide an invaluable tool for investigating the relationship between decadal variability and ENSO amplitude modulations.

Previous coupled modeling studies that have investigated decadal ENSO modulations have shown that increased ENSO variability tends to be associated with periods in which the thermocline is deeper in the eastern equatorial Pacific, while weaker ENSO variability tends to be associated with a shallower thermocline (Kirtman and Schopf 1998; Kleeman et al. 1999; Barnett et al. 1999; Federov and Philander 2000). It has been pointed out that this relationship between thermocline tilt and ENSO activity is counterintuitive, since it is in that configuration that a small vertical displacement of the thermocline would have a maximum impact on the temperature of water, which upwells into the surface mixed layer in the Niño-3 region $\left(5^{\circ} \mathrm{N}-5^{\circ} \mathrm{S}, 90^{\circ}-150^{\circ} \mathrm{W}\right)$.

The principal scientific questions we are addressing are the following: What processes are responsible for TPDV? How important are the Tropics in setting the spatial structure of TPDV? Do nonlinearities in the tropical system play an important role in TPDV, and if so, can they help to resolve the counterintuitive relationship between thermocline tilt and ENSO activity reported in previous modeling studies?

In particular, we intend to test the hypothesis that lowfrequency modulations of ENSO amplitude account for an important component of TPDV in the model, and that asymmetries in ENSO play in important role in prescribing the preferred structures of TPDV in SST and thermocline depth (Z20). In order to test this hypothesis, we turn to a 1000-yr run of a coupled oceanatmosphere model to better understand these interactions between Z20, SST, and decadal modulations of ENSO behavior. Although the ECHO-G model is characterized by an unrealistically sharp 2-yr peak in its Niño-3 SST anomaly (SSTA) spectrum, the model exhibits significant decadal modulations of its ENSO amplitude.

\section{Model description and observations}

The model used is the atmosphere-ocean coupled circulation model ECHO-G (Legutke and Voss 1999). This is similar to the model presented in the studies of Frey et al. (1997) and Schneider et al. (2002), except that ECHO-G uses T30 rather than T42 resolution in the atmosphere, and it employs a thermodynamic-dynamic sea ice model that includes the viscous plastic rheology of Hibler (1979). The same 1000-yr control run considered here has previously been analyzed by BaqueroBernal et al. (2002) for Indian Ocean variability and Marsland et al. (2003) for variability in the Southern Ocean. Details of the spinup for the coupled run are described in Legutke and Voss (1999). Flux corrections (heat and freshwater) were applied at the sea surface to prevent model drift.

The ocean component is the Hamburg ocean primitive equation model (HOPE-G; Wolff et al. 1997; Legutke and Maier-Reimer 1999; Rodgers et al. 2000), with horizontal resolution of $2.8^{\circ}$, except in the Tropics where the meridional resolution is stretched to $0.5^{\circ}$ along the equator. The ocean has 20 unevenly spaced vertical levels, with 10 of these in the upper $225 \mathrm{~m}$. The model equations are solved on an E grid, using second-order centered differencing. Vertical mixing is achieved using the parameterization of Pacanowski and Philander (1981). The atmospheric component is ECHAM4 (Roeckner et al. 1996) at T30 resolution with 19 vertical levels.

For SST data analysis, we use the Hadley Centre Sea Ice and SST dataset (HadISST) of Parker et al. (1999), which has $1^{\circ}$ horizontal resolution and which spans the period 1871-1999. This dataset represents an improved version of the Global Sea Ice and SST dataset (GISST) of Rayner et al. (1996). For thermocline depth analysis, we use the gridded upper-ocean temperature dataset of White et al. (1999) over the period 1955-99. Temperatures have been linearly interpolated in the vertical to locate the depth of the $20^{\circ} \mathrm{C}$ isotherm (Z20). 

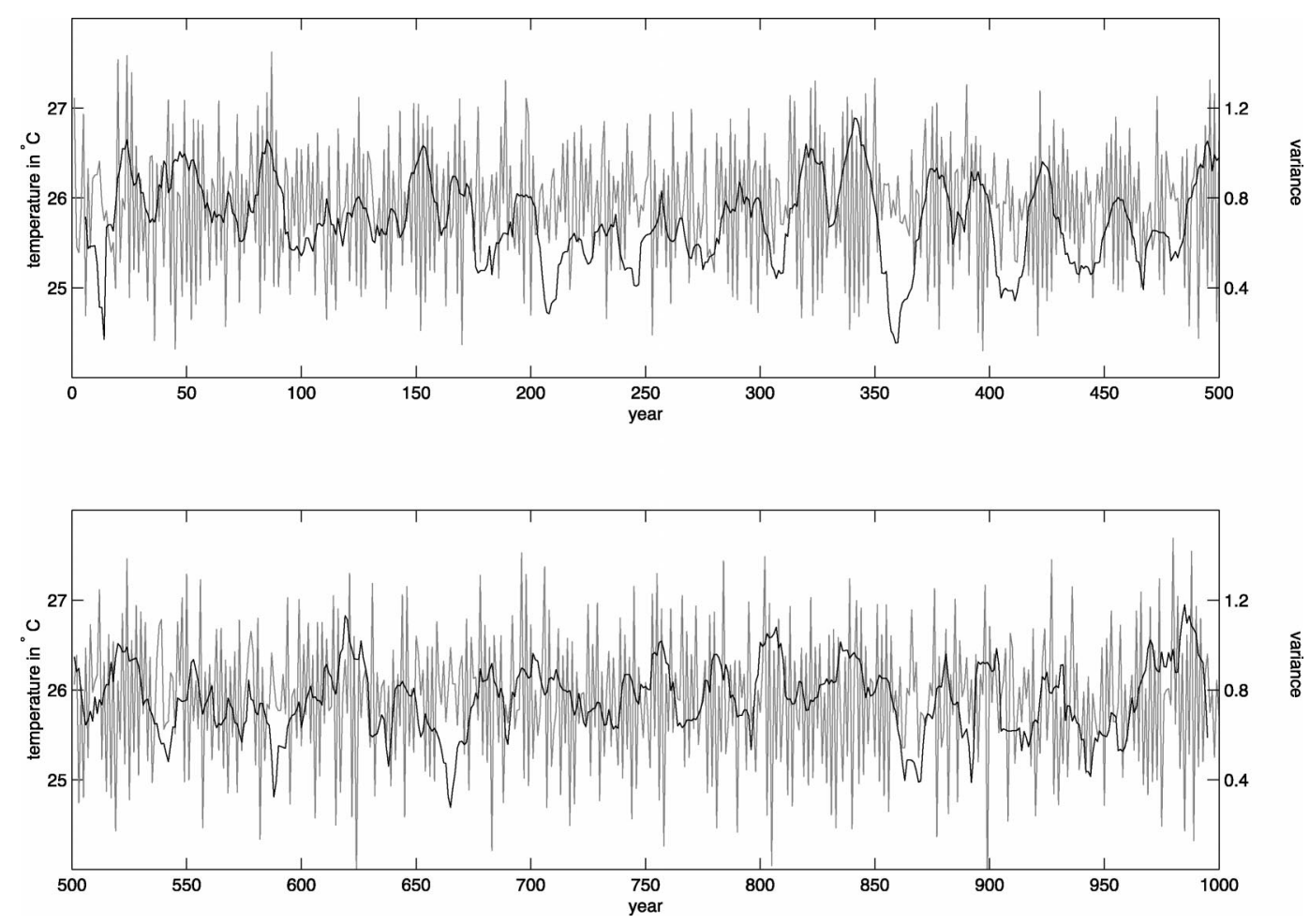

FIG. 1. Variability of annual mean SST average $\left({ }^{\circ} \mathrm{C}\right)$ over the Niño-3 region $\left(5^{\circ} \mathrm{N}-5^{\circ} \mathrm{S}, 90^{\circ}-150^{\circ} \mathrm{W}\right.$ ) (gray line) and the N3VAR index for decadal ENSO amplitude modulations (black line).

\section{Results}

The analysis presented in this section is intended to test our hypothesis that low-frequency ENSO amplitude modulations are the principal source of TPDV in the model. It is also intended to test whether this hypothesis can resolve the counterintuitive problem mentioned in the introductory section. We begin by defining an index (Z20DEC) corresponding to decadal/interdecadal variability in the zonal structure of the $20^{\circ} \mathrm{C}$ isotherm depth across the equatorial Pacific, and we relate this to another index that we derive to describe the decadal/interdecadal ENSO amplitude modulations (N3VAR). Regression analysis (with the Z20DEC index) is then used to identify perturbation structures in Z20, SST, surface wind stress, and equatorial thermocline stratification characteristic of TPDV. We then consider asymmetries in the model's characteristic El Niño and La Niña anomaly patterns of Z20 and SST to test whether ENSO asymmetries in these fields can account for the lowfrequency TPDV patterns for the same fields.

\section{a. ENSO amplitude and zonal thermocline structure}

The existence of a regular 2-yr El Niño is evident in the annual mean Niño-3 SST time series (Fig. 1), as are the decadal to multidecadal modulations of ENSO amplitude. In order to represent these low-frequency ENSO amplitude modulations, an 11-yr window has been ap- plied to the annual mean Niño-3 SSTA time series, and after detrending on this interval, the variance over the $11-\mathrm{yr}$ window has been calculated. This results in an index N3VAR (thick black line in Fig. 1) for the ENSO amplitude modulations which, for example, is able to identify the decade surrounding year 340 as being a time of very high variance, and the decade surrounding year 358 as being a period of relatively low variance.

Next we consider empirical orthogonal functions (EOFs) of the zonal structure of the equatorial thermocline (here characterized by $\mathrm{Z} 20$ averaged over $5^{\circ} \mathrm{N}-$ $5^{\circ} \mathrm{S}$ ) over longitudes spanning $150^{\circ} \mathrm{E}$ to $80^{\circ} \mathrm{W}$. The first EOF is shown in Fig. 2a. It explains $80.45 \%$ of the variance, and its principal component (PC) has a correlation of 0.93 with the Niño-3 SSTA index. Its spectrum has a similarly dominant peak at 2 yr. Physically, this corresponds to ENSO variability, which is characterized by changes in Z20 along the equator that have the same sign throughout the central and eastern equatorial Pacific. The variations are maximum near $125^{\circ} \mathrm{W}$.

The second EOF (Fig. 2b) explains only $14.4 \%$ of the variance and is well separated from the third EOF (not shown), which explains only $3.4 \%$. The second EOF reveals a zero crossing at $125^{\circ} \mathrm{W}$ and represents changes in the zonal structure of the thermocline along the central-eastern equatorial Pacific.

Now we consider the same Z20 field, except this time an 11-yr running mean temporal smoothing has been 

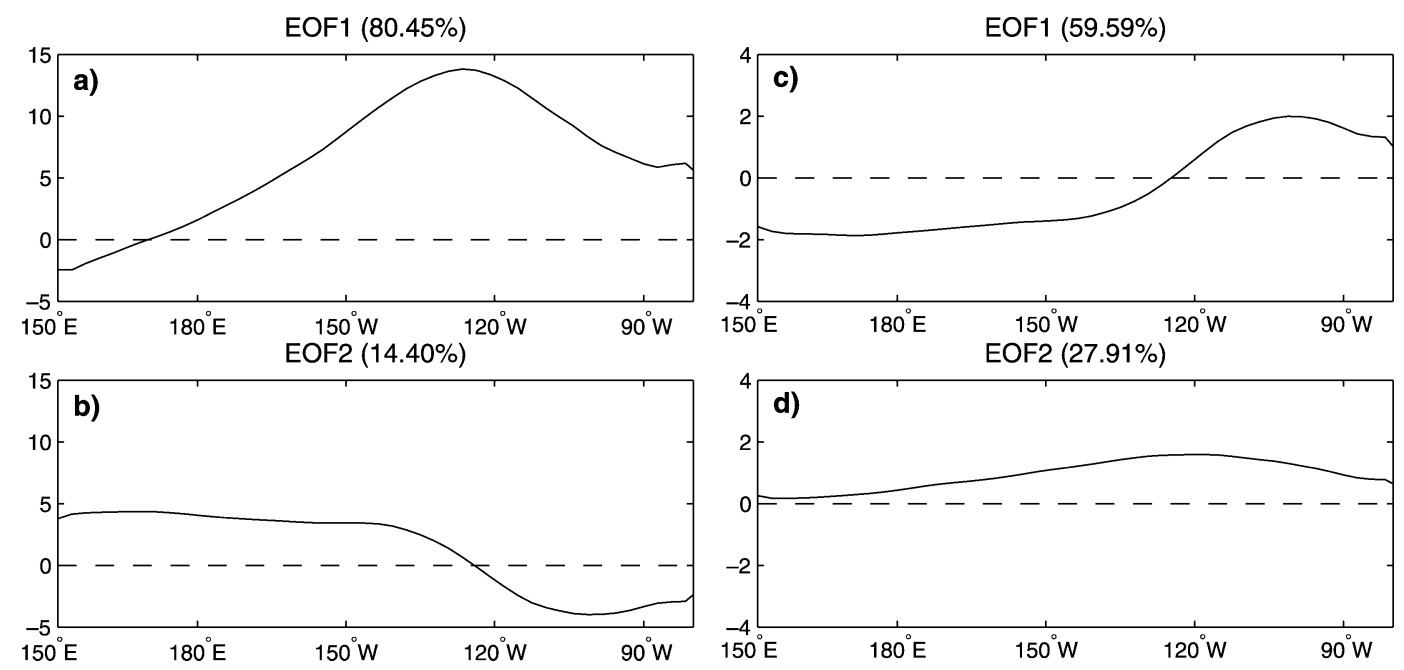

FIG. 2. EOFs of $\mathrm{Z} 20$ (averaged over $5^{\circ} \mathrm{N}-5^{\circ} \mathrm{S}$ ) across the equator (between $150^{\circ} \mathrm{E}$ and $80^{\circ} \mathrm{W}$ ) in the Pacific: (a) first and (b) second EOF of the annual mean Z20, and (c) first and (d) second EOF of the 11-yr running mean Z20. Units are in $\mathrm{m}$.

applied to it. The first EOF of this filtered field (Fig. 2c), which explains $59.6 \%$ of the variance, bears a strong resemblance to the EOF shown in Fig. $2 \mathrm{~b}$ and represents low-frequency changes in the zonal structure of the $20^{\circ} \mathrm{C}$ isotherm across the equator. The PC corresponding to this EOF, which we refer to henceforth as Z20DEC, has a correlation of 0.73 with the N3VAR index, but does not correlate with decadal variations of Niño-3 SSTA. This PC, which represents low-frequency changes in the zonal thermocline structure, does not have a decadal peak in its spectrum. In this respect our results differ from those of Timmermann and Jin (2002), who identified a decadal peak in the spectrum for their thermocline variations.

The second EOF of the decadal Z20 variations (Fig. 2d) explains $27.9 \%$ of the variance. Its PC has a correlation of 0.52 with the Niño-3 SSTA index, to which an 11-yr smoothing has been applied. This indicates that decadal changes with an ENSO-like structure in Z20 and SST (not shown) are also present in the model.
Both the N3VAR (solid line) and the Z20DEC (dashed line) indices are superposed in Fig. 3, revealing that changes in ENSO amplitude are related to changes in the zonal thermocline structure for the model. The sense of the correlation is such that the $20^{\circ}$ isotherm surface tends to be flatter (deeper in the east and shallower in the west) during periods when ENSO amplitude is large. A lead-lag correlation between the N3VAR and Z20DEC indices (not shown) indicates that they vary in phase. Thus there is no indication in the model that low-frequency changes in the equatorial thermocline structure precede changes in ENSO amplitude, or vice versa.

Next we consider the Z20DEC index regressed against three different two-dimensional fields. The first field we consider is annual mean Z20, which is shown in Fig. 4. In the eastern equatorial Pacific, there is relative hemispheric symmetry in that there is a local maximum both to the north and to the south of the equator. To the west, the pattern is characterized by a large hemi-

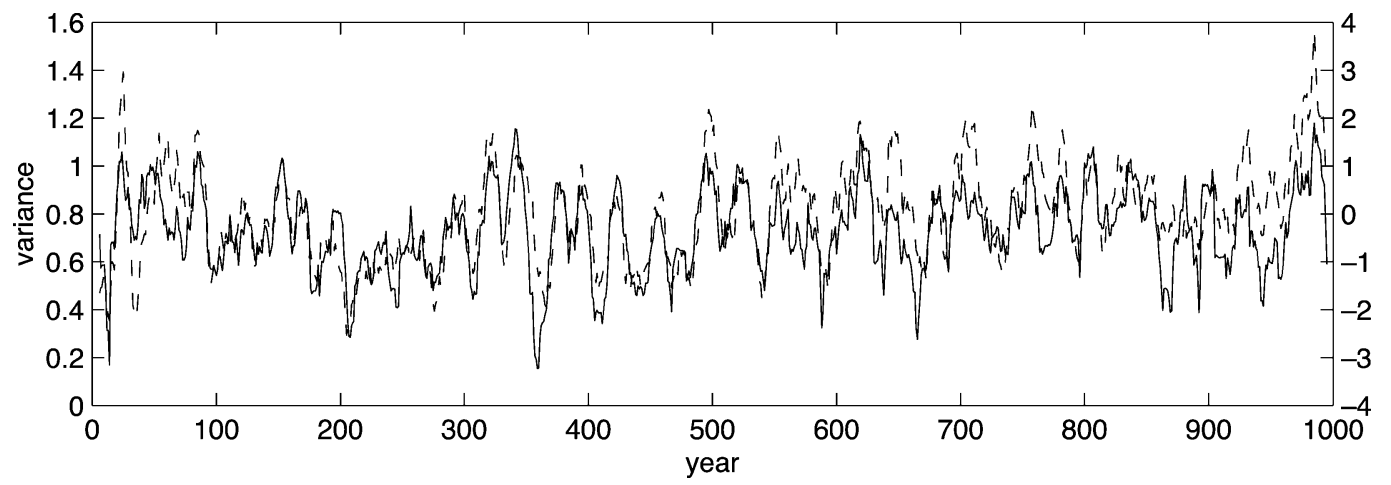

FIG. 3. N3VAR (solid line) and the PC corresponding to the first decadal EOF of Z20 in Fig. 2c (Z20DEC) (dashed line). 


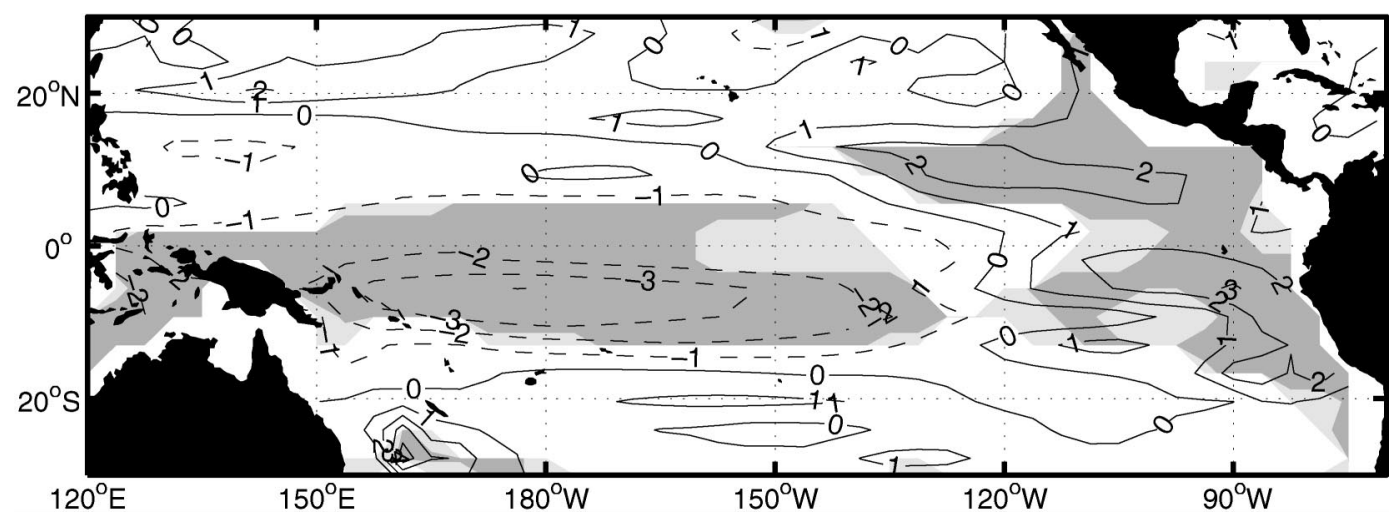

FIG. 4. Regression of the global Z20 field against the Z20DEC index shown in Fig. 3b in ECHO-G (contour lines in m). Significance levels of $90 \%$ and $95 \%$ are shown in gray.

spheric asymmetry. An elongated thermocline depth anomaly can be seen to extend from the western boundary to $150^{\circ} \mathrm{W}$ between $5^{\circ}$ and $10^{\circ} \mathrm{S}$, and this has the same sign as the $\mathrm{Z} 20$ depth excursions along the equator in the warm-pool region. There is no correspondingly large Z20 anomaly in the Northern Hemisphere over this same range of longitudes.

The regression pattern for annual mean SST is shown in Fig. 5a. It is characterized by a dipole structure in the zonal direction between $10^{\circ} \mathrm{N}$ and $10^{\circ} \mathrm{S}$, with a strong local maximum near $8^{\circ} \mathrm{S}, 90^{\circ} \mathrm{W}$ and a weaker local minimum near $0^{\circ}, 180^{\circ}$. The relative hemispheric
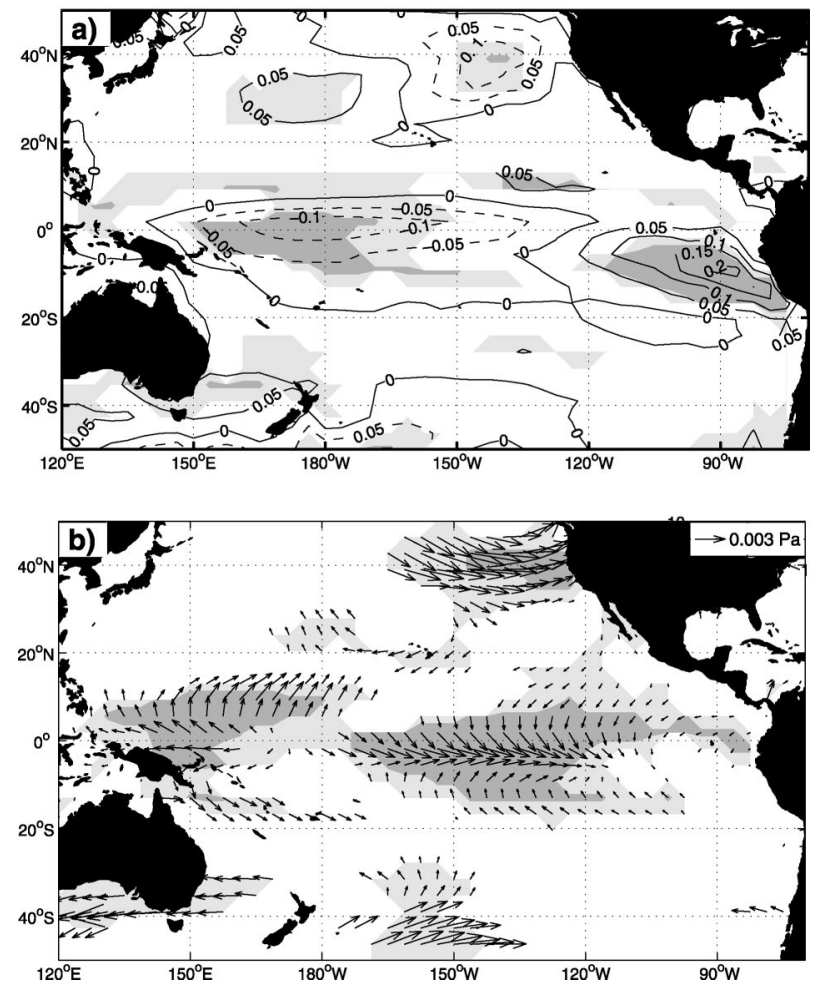

FIG. 5. Same as Fig. 4 but for annual mean (a) SST $\left({ }^{\circ} \mathrm{C}\right)$ and (b) surface wind stress $(\mathrm{Pa})$. symmetry seen in the east for Z20 is not reflected in SST, since strong SST changes are found only south of the equator. When the thermocline is deep in the east and shallow in the west, the temperatures are warm in the east and cold in the west. This pattern is very similar to the decadal SST pattern achieved by computing EOFs of SST to which an 11-yr low-pass filter has been applied (decadal EOF not shown).

Figure $5 \mathrm{~b}$ shows the equivalent regression pattern for the surface wind stress $(\boldsymbol{\tau})$. The cold (warm) patches of SST correspond to divergence (convergence) in this field. Associated with the asymmetry about the equator in the SST regression pattern in the eastern equatorial Pacific (Fig. 5a), there is a southward component of $\tau$ across the equator between $160^{\circ}$ and $120^{\circ} \mathrm{W}$.

At first glance, these decadal perturbation structures in Z20, SST, and $\boldsymbol{\tau}$ appear to be in dynamical balance. The changes in the slope of the thermocline appear to be consistent with the change in basin-scale wind stress across the equator, and the structure of the wind stress pattern appears to be consistent with a convergence of surface winds in regions where SST perturbations are warm and divergent where SST perturbations are cool.

\section{b. ENSO nonlinearities}

We now turn our attention to differences in the Z20 and SST anomaly patterns associated with the model's El Niño and La Niña states, respectively. We begin by comparing the Z20 structures of a composite El Niño and a composite La Niña for the model. The composites are calculated by considering the annual mean Niño-3 SSTA time series for the model (Fig. 1) and using a criterion of one standard deviation in this index to characterize El Niño and La Niña events. As a result of the weak skewness in Niño-3 SSTA, as well as weak decadal variability in the 11-yr running mean of Niño-3 SSTA, choosing plus or minus one standard deviation as a criterion for the composites results in the choice of similar numbers of El Niño and La Niña events. Significance for asymmetry patterns is estimated with 

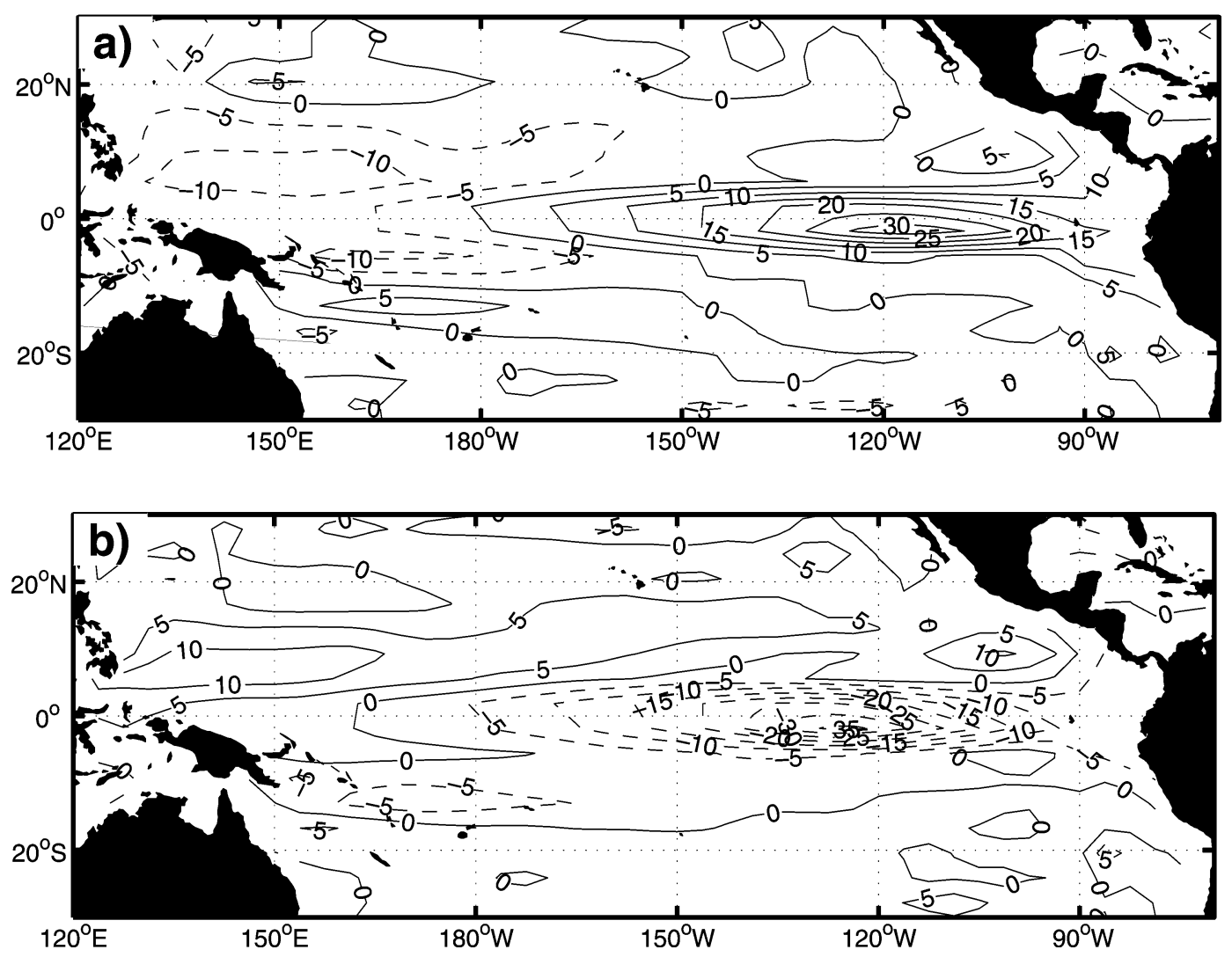

FIG. 6. Composites of the Z20 structure for (a) El Niño and (b) La Niña in ECHO-G (m). Since significance exceeds $90 \%$ almost everywhere, significance levels are not shown.

a hypothesis test using a two-sided $t$ test, and for the El Niño and La Niña composites a one-sided $t$ test is used.

The composite Z20 structure for the model El Niño is shown in Fig. 6a. Focusing first on the structure averaged over $5^{\circ} \mathrm{N}-5^{\circ} \mathrm{S}$, we see that this structure is maximum near $115^{\circ} \mathrm{W}$, and there is a zero crossing along the equator near $180^{\circ}$. For the composite La Niña Z20 (Fig. 6b), the structure along the equator is quite similar to that shown in Fig. 6a, except that it is shifted by approximately $15^{\circ}$ longitude to the west relative to the El Niño pattern. For this pattern, the zero crossing for the $\mathrm{Z} 20$ field (for an average over $5^{\circ} \mathrm{N}-5^{\circ} \mathrm{S}$ ) is near $160^{\circ} \mathrm{E}$.

The sum of the Z20 structures for the composite El Niño and the composite La Niña is shown in Fig. 7. This residual reflects asymmetries in the Z20 structure between the warm and cold phases of the model's ENSO

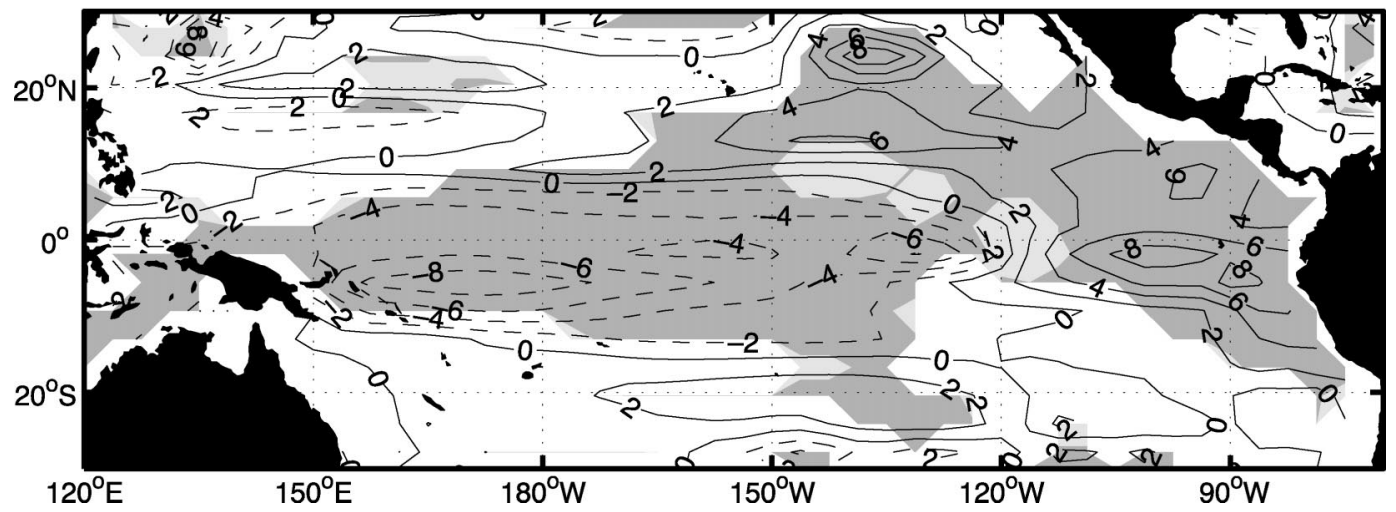

FIG. 7. Asymmetry of Z20 for El Niño and La Niña in ECHO-G (sum of Figs. 6a and 6b), in units of m. Significance levels of $90 \%$ and $95 \%$ are shown in gray. 

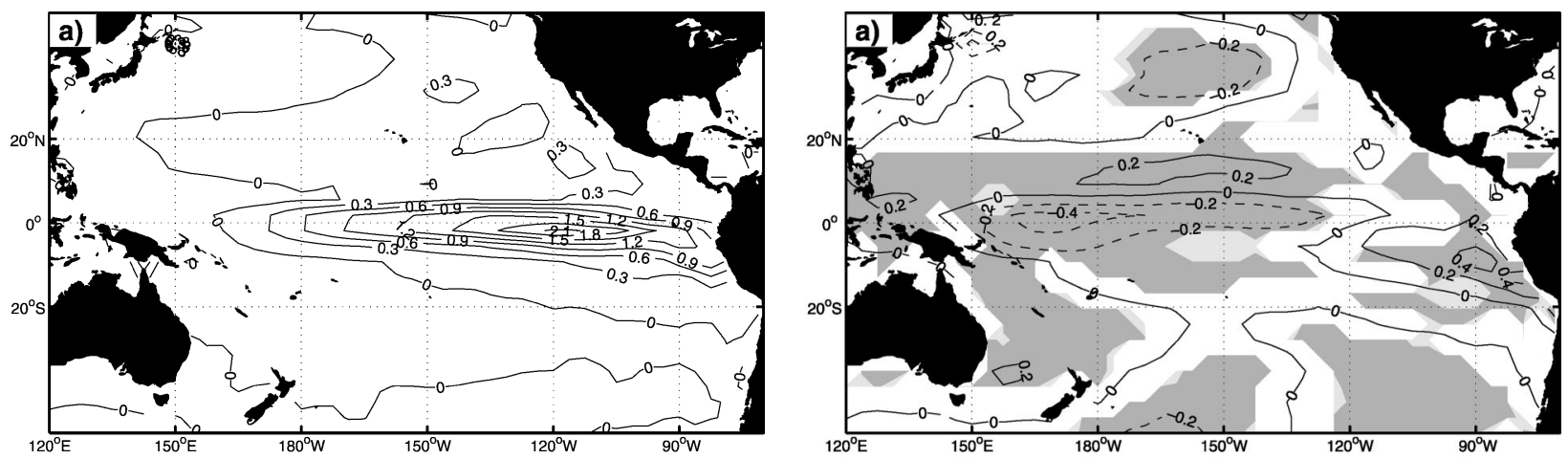

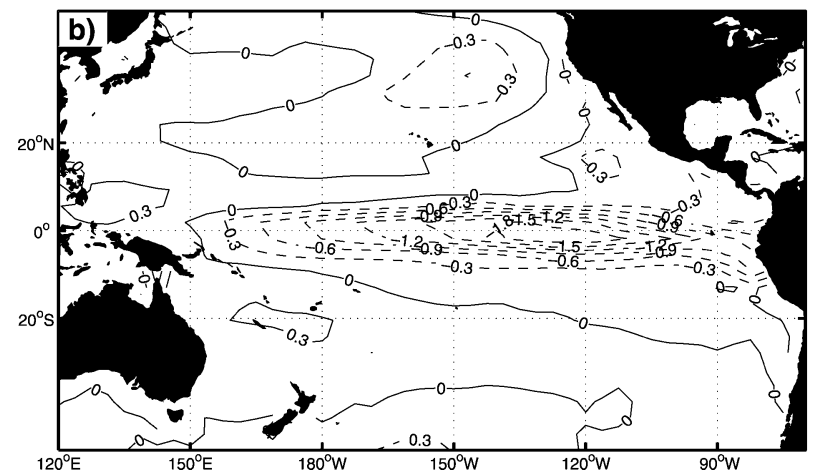

FIG. 8. Composites of the SST structure for (a) El Niño and (b) La Niña, in units of ${ }^{\circ} \mathrm{C}$. Since significance exceeds $90 \%$ almost everywhere, significance levels are not shown.

variability. The salient features of this pattern are its slope along the equator, with a pivot (zero crossing) near $120^{\circ} \mathrm{W}$, as well as a local maximum in the western Pacific to the south of the equator along $6^{\circ} \mathrm{S}$. Comparison of the residual with the two composites in Figs. 6a and $6 \mathrm{~b}$ reveals that this structure along $6^{\circ} \mathrm{S}$ is largely due to a local shoaling during El Niño that is not compensated by a deepening during La Niña. Thus, the average over a complete ENSO cycle is not zero. Importantly, there is a striking similarity between this pattern and the regression pattern for Z20 shown in Fig. 4. This gives credence to the hypothesis that we are testing, namely, that the dominant decadal pattern in Z20 (Fig. 4) is the consequence, not the cause, of ENSO amplitude modulations.

We employ the same technique to define a composite SST perturbation structure for the model's El Niño and La Niña states. The composite El Niño (Fig. 8a) is characterized by SST anomalies that are maximum along the equator near $115^{\circ} \mathrm{W}$. This corresponds to the position of the maximum thermocline displacement for the El Niño Z20 composite in Fig. 6a, as maximum temperature anomalies correspond to regions of maximum thermocline displacement. These positive anomalies extend to the eastern boundary, and at the coast of Peru they extend meridionally from the equator to approximately $10^{\circ} \mathrm{S}$. The pattern of the composite La Niña SST perturbation (Fig. 8b) is similar to that of the composite

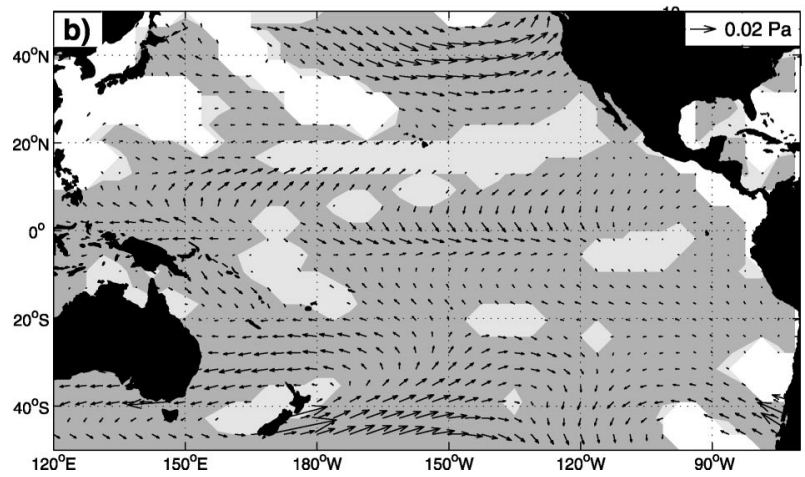

FIG. 9. Asymmetry patterns in (a) SST $\left({ }^{\circ} \mathrm{C}\right)$ and (b) surface wind stress (Pa). Significance levels of $90 \%$ and $95 \%$ are shown in gray.

El Niño pattern; however, as with the composite Z20 patterns shown in Fig. 6, the La Niña composite pattern is shifted slightly to the west relative to the El Niño composite pattern, by approximately $15^{\circ}$ longitude.

The sum of the El Niño and La Niña SST composites is shown in Fig. 9a. This residual pattern exhibits a positive maximum in the eastern Pacific that lies to the south of the equator, centered near $10^{\circ} \mathrm{S}, 90^{\circ} \mathrm{W}$. The pattern also exhibits a negative maximum centered along the equator to the west of $120^{\circ} \mathrm{W}$. This dipole structure in SST across the equatorial Pacific is very similar to the structure seen in the regression pattern for SST (Fig. 5a).

The corresponding ENSO asymmetry pattern for the surface wind stress $(\boldsymbol{\tau})$ is shown in Fig. $9 \mathrm{~b}$. The pattern is again very similar to that found for the regression pattern for $\tau$ (Fig. 5b). In the eastern equatorial Pacific, there is a region of convergence of the stress field along $5^{\circ} \mathrm{S}$ between $90^{\circ}$ and $110^{\circ} \mathrm{W}$. In the western equatorial Pacific, there is a region of divergence that is centered just to the north of the equator near $170^{\circ} \mathrm{E}$. These regions of convergence and divergence are associated with the warm and cool regions that were shown in Fig. 9a.

In the North Pacific, there is also a strong similarity between the ENSO asymmetry pattern for $\tau$ and the regression pattern for $\boldsymbol{\tau}$ (Fig. $5 \mathrm{~b}$ ). As our focus is the equatorial region, we merely point out here that this provides a plausible explanation for the decadal SST 

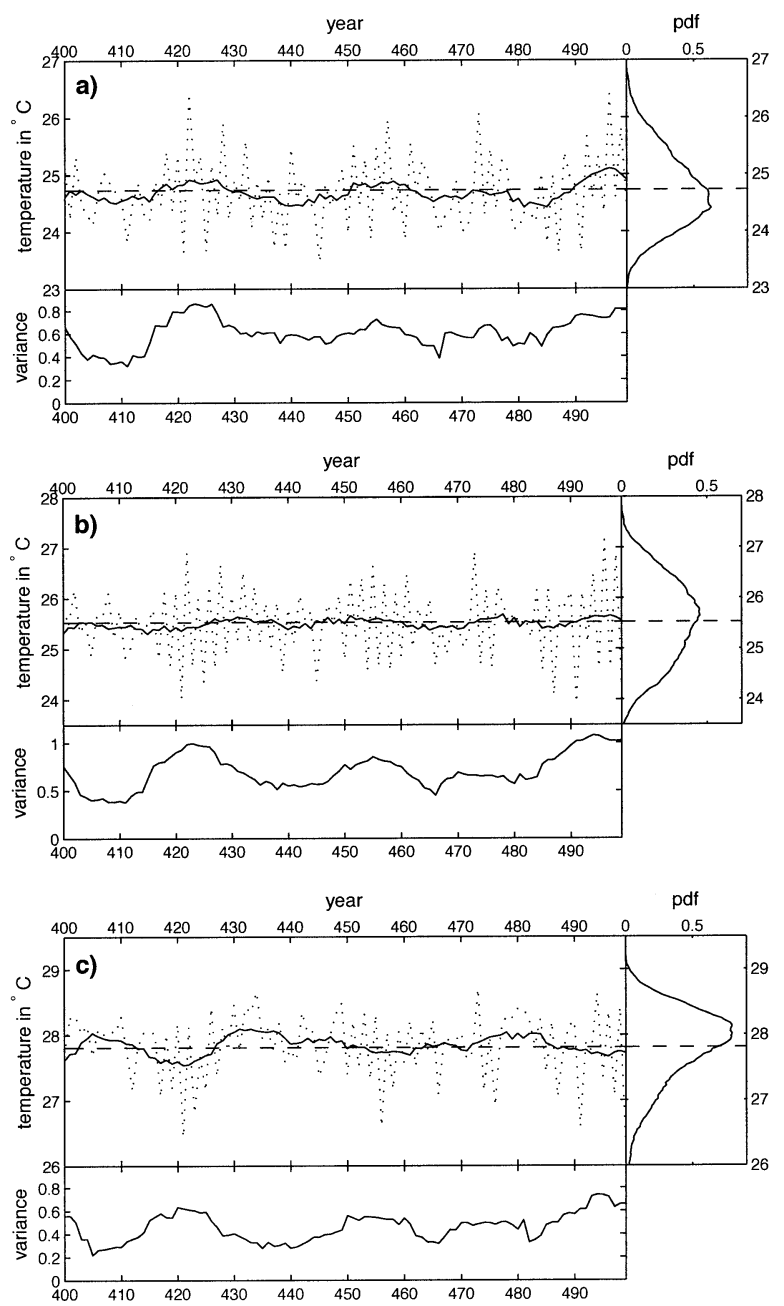

FIG. 10. Mean SST indices for different regions in the tropical Pacific for ECHO-G: the (a) Niño-12, (b) Niño-3, and (c) Niño-4 regions. The annual mean temperature is the dotted line and the 11yr running mean temperature is the solid line in the upper panels of (a)-(c), while the variance within an 11-yr window is shown in the lower panel, and the probability density function for the annual mean temperature is shown in the right-hand panels of (a)-(c).

perturbation near $40^{\circ} \mathrm{N}$ identified by regressing against Z20DEC (Fig. 5a). Although this extratropical SST structure does not constitute the dominant structure of North Pacific decadal variability for the model, this SST signal associated with ENSO nonlinearities is not insignificant in the North Pacific.

Thus far our analysis has focused on spatial asymmetries in the model output fields associated with ENSO variability. Now we turn our attention to the skewness of commonly used indices of equatorial Pacific variability, namely, Niño-12 SST (averaged over $0^{\circ}-10^{\circ} \mathrm{S}$, $80^{\circ}-90^{\circ} \mathrm{W}$ ), Niño-3 SST (averaged over $5^{\circ} \mathrm{N}-5^{\circ} \mathrm{S}, 90^{\circ}-$ $150^{\circ} \mathrm{W}$ ), and Niño-4 SST (averaged over $5^{\circ} \mathrm{N}-5^{\circ} \mathrm{S}$, $\left.160^{\circ} \mathrm{E}-150^{\circ} \mathrm{W}\right)$. For each of these indices, several time series are shown for the years 400-500 (arbitrarily chosen) in Fig. 10.
The variations of the annual mean Niño-12 SST is shown in Fig. 10a as a series of dots. An index obtained by filtering the Niño-12 SST with an 11-yr running mean (N12FIL) is superimposed over the annual mean time series, and the long-term mean (for the entire $1000 \mathrm{yr}$ ) is shown as a dashed line. The N12FIL curve reveals interdecadal variability of the spatially averaged temperature for this region. An N12VAR index, analogous to the N3VAR index described earlier, is shown in the lower panel of Fig. 10a. The N12VAR index and N12FIL have a correlation of 0.55 . The right-hand panel of Fig. 10a shows the probability density function (PDF) of SST within Niño-12 for the entire 1000-yr run. The PDF was estimated using a box-shaped kernel estimation. The skewness (also calculated for the entire 1000yr run) is 0.35, and clearly large warm excursions of SST are more frequent than large cool excursions of SST. The PDF in Fig. 10a reveals that the long-term mean in SST is slightly different from the most probable state, whereas they would be the same for a linear system.

The equivalent results for the Niño-3 region are shown in Fig. 10b. The 11-yr running mean of SST for this region (N3FIL) shows smaller variations than were found for Niño-12. The correlation between N3FIL and N3VAR is 0.01, and the skewness for Niño-3 SST is very weak $(-0.007)$. This weak skewness helps to explain why the decadal changes in the Niño-3 SSTA time series (Fig. 10b) are dominated by ENSO amplitude modulations, with only small changes in N3FIL.

Next we consider the Niño-4 region in Fig. 10c. Once again the annual mean Niño-4 SST values are shown as a series of dots. The N4FIL index (11-yr running mean of Niño-4 SST) indicates higher variability than was found for the N3FIL index, and the N4VAR index (again analogous to the N3VAR index) is shown in the lower panel, revealing decadal changes in the amplitude of Niño-4 SST variations. The changes in N4VAR are anticorrelated (correlation $=-0.6$ ) with N4FIL, and the skewness for Niño-4 is -0.77 . Large cool temperature excursions for this region are more common than large warm excursions, and the PDF demonstrates that the mean SST of the Niño-4 region does not coincide with the most probable Niño-4 SST, as it would be if the system were linear.

\section{c. Changes in stratification}

Next we consider variability in the thermocline stratification of the eastern equatorial Pacific. Here we are interested in identifying whether there is low-frequency variability in stratification in the Niño-3 region, and if so, what might be the cause. Zebiak and Cane (1991) have shown that the ENSO variability in their coupled model is strongly sensitive to prescribed changes in ocean stratification. We begin in Fig. 11 by defining the thermocline stratification for the model's eastern and central equatorial Pacific upwelling region as the dif- 

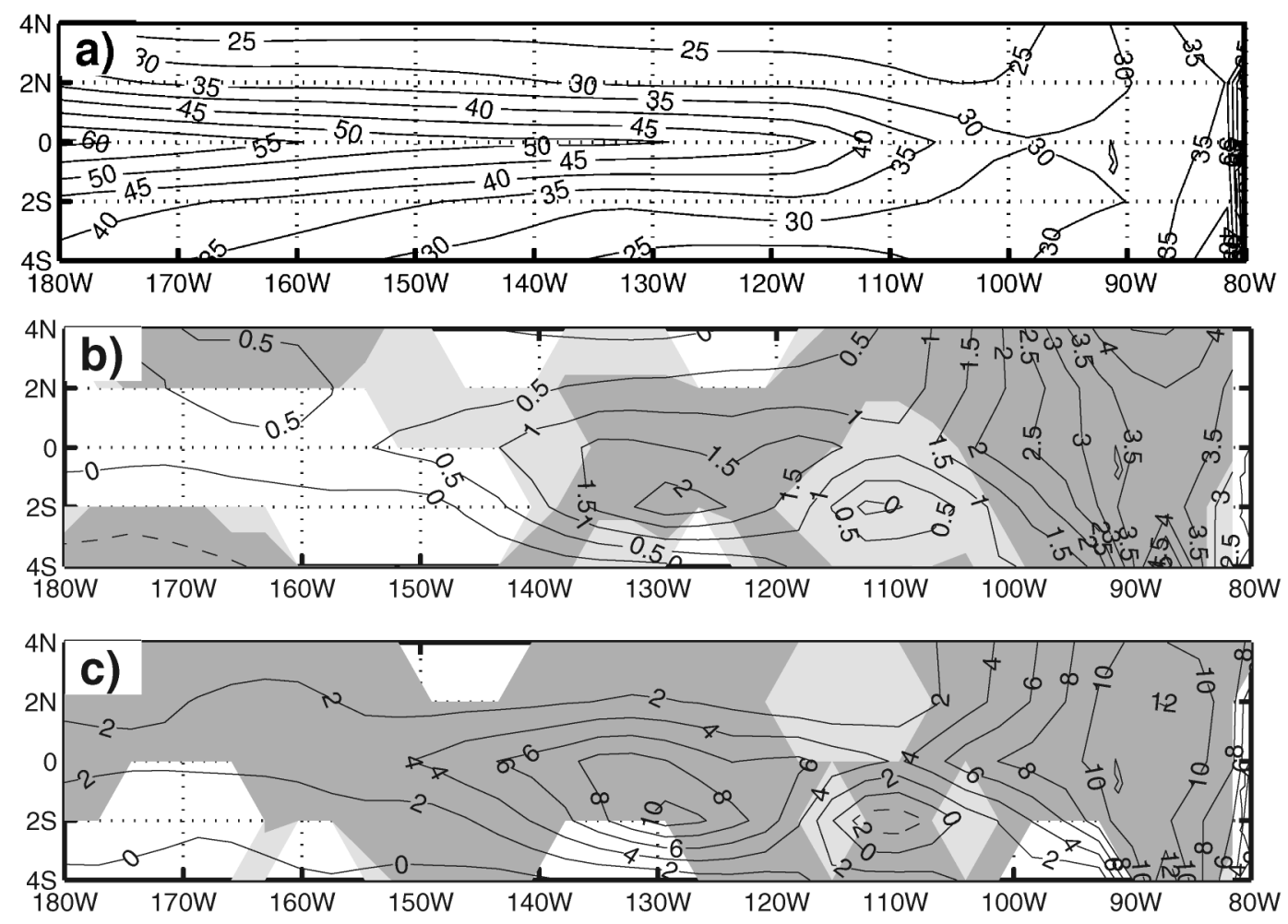

FIG. 11. (a) Mean stratification, defined as the average depth difference between the $\sigma_{0}=25$ and $\sigma_{0}=26$ isopycnal surfaces over the full $1000 \mathrm{yr}$ of the model run, (b) regression of annual mean stratification on the Z20DEC index, and (c) asymmetry of stratification for El Niño and La Niña in ECHO-G. Units are in m.

ference between the depths of the $\sigma_{0}=26.0$ and $\sigma_{0}=$ 25.0 potential density surfaces. Along the equator, the $\sigma_{0}=25.0$ surface corresponds roughly to the $21^{\circ} \mathrm{C}$ isotherm, and the $\sigma_{0}=26.0$ surface corresponds roughly to the $16^{\circ} \mathrm{C}$ isotherm. The model's pycnocline is centered near $\sigma_{0}=25.5$, and thus the surfaces discussed straddle the pycnocline. Nevertheless, the results presented in this section are qualitatively the same when the stratification is defined for a shallower layer in the thermocline (bounded by $\sigma_{0}=24.0$ and $\sigma_{0}=25.0$ ).

The time-averaged thickness of this layer for the entire 1000-yr ECHO-G experiment is shown in Fig. 11a over the region $\left(4^{\circ} \mathrm{N}-4^{\circ} \mathrm{S}, 180^{\circ}-80^{\circ} \mathrm{W}\right)$. The figure reveals large meridional gradients in the mean layer thickness between the equator and $4^{\circ} \mathrm{N}$ and $4^{\circ} \mathrm{S}$ in either hemisphere, with reduced stratification near the equator. This meridional structure is consistent with observations (see Fig. 2 of Wyrtki and Kilonsky 1984). Associated with the geostrophic component of the equatorial undercurrent (EUC) the lower thermocline has a bowl shape. Associated with the equatorial upwelling (and the partly geostrophic EUC), the upper thermocline has a dome structure for the mean state. In terms of zonal structure, a zonal gradient exists over the Niño-3 region, with values of order $50 \mathrm{~m}$ at $150^{\circ} \mathrm{W}$, and decreasing to values of order $30 \mathrm{~m}$ at $90^{\circ} \mathrm{W}$. This zonal structure is associated with a weakening of the EUC to the east.
The regression map of the thermocline stratification onto the Z20DEC index (Fig. 11b) reveals changes in stratification that occur on decadal time scales within the Niño-3 region. A maximum change in layer thickness (decrease in stratification) is found near $2^{\circ} \mathrm{S}$, $130^{\circ} \mathrm{W}$, while another maximum of approximately twice the amplitude is found near $85^{\circ} \mathrm{W}$. Between these two maxima there is a minimum along the equator between $130^{\circ}$ and $110^{\circ} \mathrm{W}$. Thus the stratification averaged over the Niño-3 region is decreased during periods when the Z20DEC index is positive (i.e., when the mean zonal thermocline tilt is reduced and ENSO variability is stronger).

Figure 11c shows the ENSO residual structure (El Niño composite plus La Niña composite) of the stratification for the eastern equatorial Pacific. It is distinct from the structures of the composites associated with El Niño or La Niña conditions (not shown). The residual is positive throughout most of the Niño-3 region, and the structure is very similar to that shown in the regression map (Fig. 11b). As in the case of decadal Z20, we interpret this to mean that the decadal modulations of the stratification are the result, not the cause, of lowfrequency ENSO amplitude modulations. The fact that the residual stratification is weaker when ENSO variability is larger is counterintuitive, since one would expect weaker stratification to lead to diminished ENSO 


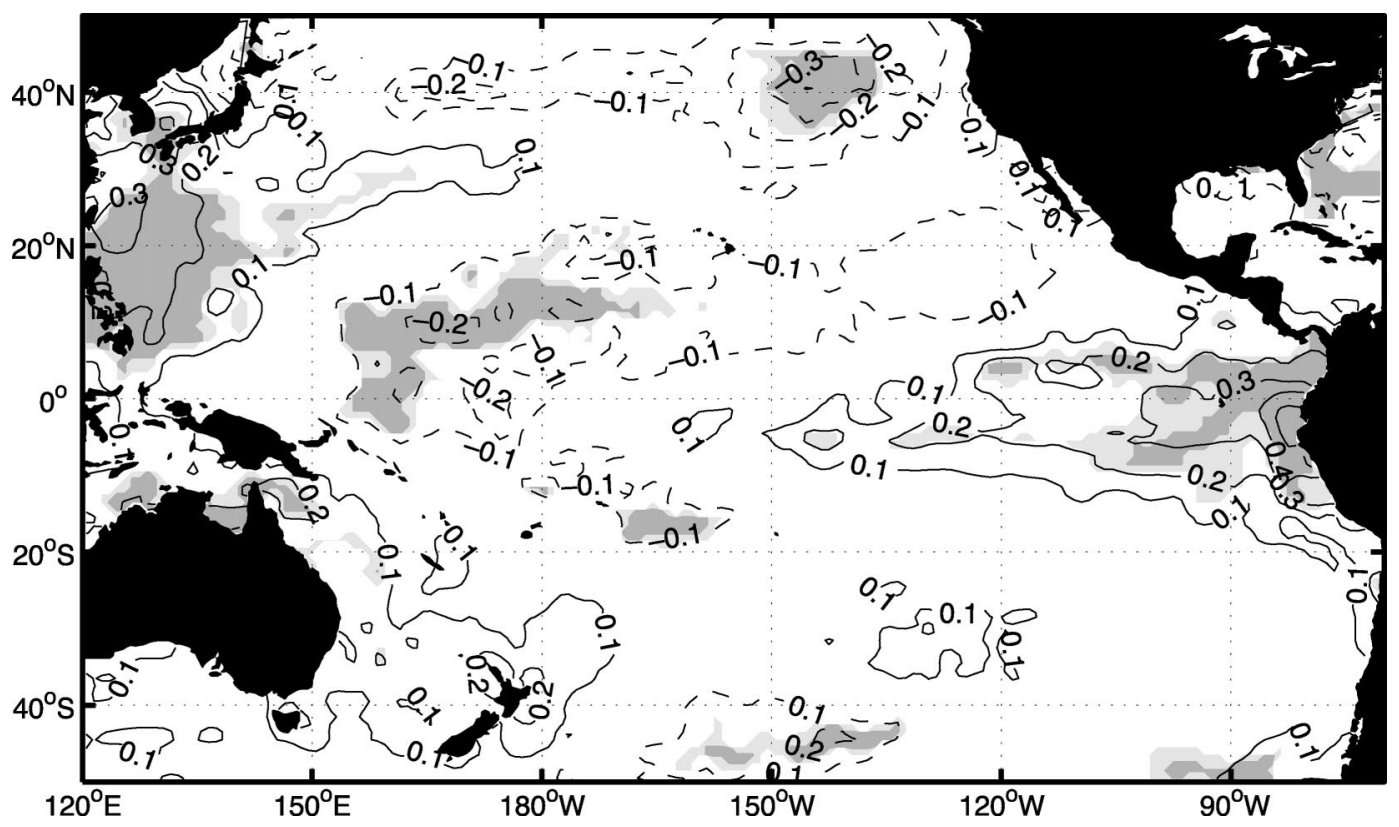

FIG. 12. Asymmetry of SST for El Niño and La Niña in observed SST of HadISST, in units of ${ }^{\circ} \mathrm{C}$. Significance levels of $90 \%$ and $95 \%$ are shown in gray.

amplitude. As with the counterintuitive problem involving thermocline depth mentioned in the introductory section, our interpretation offers a resolution to this problem.

\section{Observations}

Next we turn our attention to the HadISST data of Parker et al. (1999), which spans the years 1871-1999. Once again using one-standard-deviation outliers in Niño-3 SSTA to characterize El Niño and La Niña events, we have constructed the residual SST structure for the data (Fig. 12). This pattern has some important similarities to the structure found in the model (Fig. 9a). To the east of $120^{\circ} \mathrm{W}$, both are positive along the equator, indicating that the El Niño warming impact on SST is larger than the cooling due to La Niña between $10^{\circ} \mathrm{N}$ and $10^{\circ} \mathrm{S}$ in the eastern Pacific. To the east of $120^{\circ} \mathrm{W}$, both the model and data give maxima in their residual pattern that lie to the south of the equator. Thus the HadISST data lend support to the idea that the asymmetry in ECHO-G is not a model artifact.

Differences between the model and the HadISST residual patterns are larger in the central equatorial Pacific. The model residual exhibits a negative temperature anomaly structure along the equator from $150^{\circ} \mathrm{E}$ to $120^{\circ} \mathrm{W}$, whereas the data exhibit a positive temperature anomaly structure over this same region. One likely explanation for this discrepancy is that for the central equatorial Pacific the model SST is overly sensitive to perturbations in thermocline depth along the equator. This allows SSTs to become too cold during La Niña events, when the thermocline shoals in this region. This systematic error is at least in part due to limitations of the mixing scheme (Pacanowski and Philander 1981) in the ocean model component. More generally, there is disagreement between the model and the data over the warm-pool region.

The ENSO SST asymmetry for the HadISST (Fig. 12 ) is very similar to the spatial distribution of "skewness" shown by Burgers and Stephenson (1999) in their Fig. 3a. [Their analysis was performed using the monthly mean EOF interpolated SST fields for 1950-97 of Smith et al. (1996).] This is not surprising, as skewness toward large positive values, which they identify in the region just to the south of the equator in the eastern equatorial Pacific $\left(0^{\circ}-10^{\circ} \mathrm{S}, 90^{\circ}-120^{\circ} \mathrm{W}\right)$, indicates that warm extremes are more likely than cold extremes. This is qualitatively what we have identified by considering the ENSO residual.

The dynamical reason for the asymmetry pattern in the warm pool (or least its eastern end) could be that the warm pool is able to cool during La Niña if strong easterlies cause evaporation or upwelling anomalies. However, it is unable to get much warmer than about $30^{\circ} \mathrm{C}$ because of the effect of cloud feedbacks. The far eastern equatorial Pacific can warm during El Niño if the thermocline gets deep. But it does not cool (as much) during La Niña because wind anomalies are mostly confined to the central Pacific (easterly anomalies occur when the zonal SST gradient is large, not when it is uniformly cold). This scenario (B. Kessler 2004, personal communication) could explain why La Niña anomalies in Z20 and SST are more pronounced in the west, and El Niño anomalies in Z20 and SST are more pronounced in the east. 

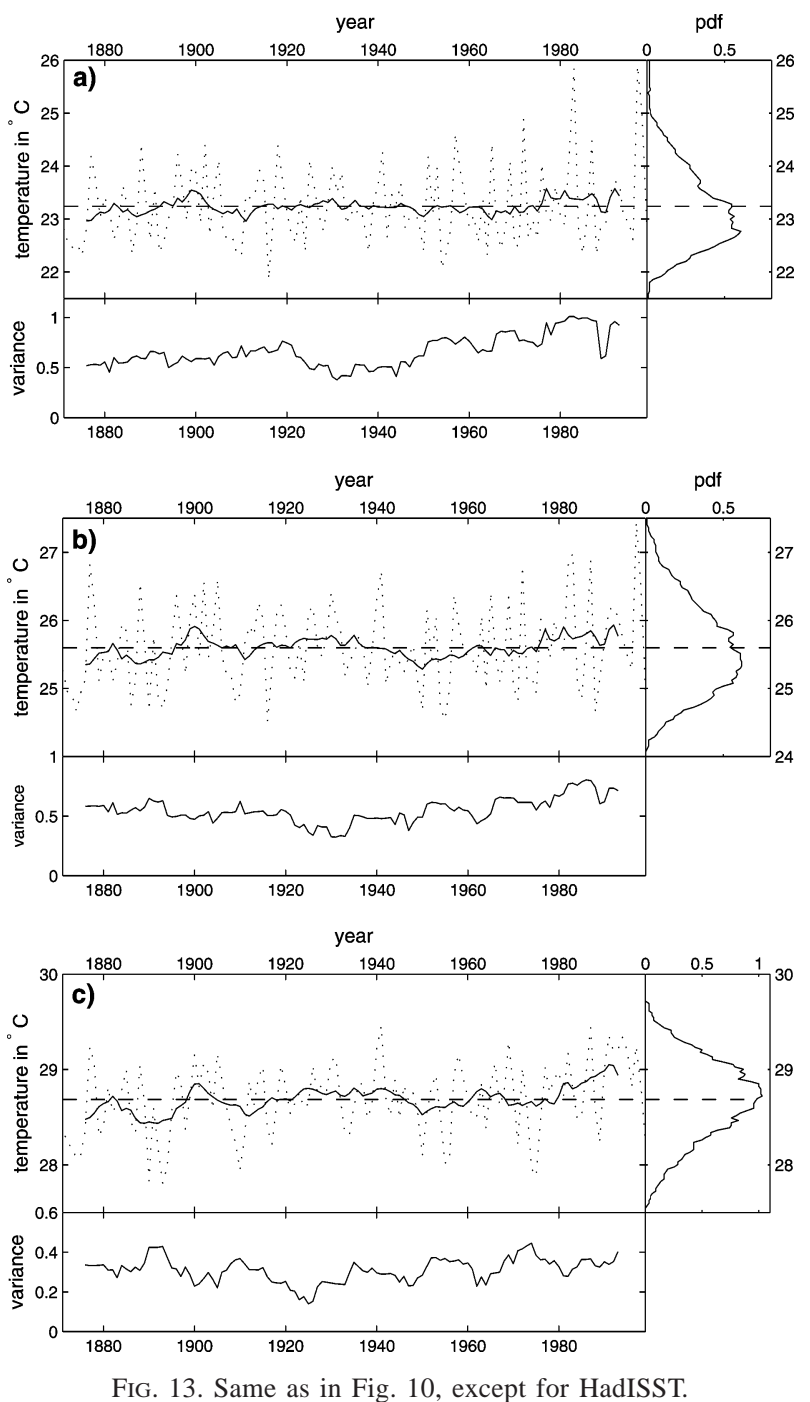

We now turn our attention to the skewness in the HadISST data (Fig. 13), using the same schematic representation that was used in Fig. 10. Figures 13a, 13b, and $13 \mathrm{c}$ show the annual mean SST series in the Niño-12, Niño-3, and Niño-4 regions, respectively, as a series of dots. For the HadISST data, the skewness of the Niño12 index is 1.001, and the correlation between the N12VAR and N12FIL indices is 0.33 (to $90 \%$ significance level). The PDF for Niño-12 SST in the HadISST dataset reveals that the long-term mean in SST for this region is not the most probable state, and this is an expression of the extent to which this region behaves nonlinearly. The Niño-12 nonlinearity is sufficiently pronounced that the rectifier effect could well be an important player for decadal variability in this region.

The skewness of the Niño-3 index for the HadISST data is -0.48 , and the correlation between the N3VAR and N3FIL indices is 0.08 . The Niño-4 index for the data has a skewness of -0.26 , and the correlation between the N4VAR and N4FIL indices is -0.31 . Thus while in the model the skewness of the Niño-4 index is larger than that of the Niño-3 index, this situation is reversed for the observations. Once again, this reflects differences in the modeled (Fig. 9a) and observed (Fig. 12) SST asymmetry patterns.

It was mentioned earlier that subsurface temperature measurements in the Pacific predating 1980 are quite sparse, so that it is difficult to validate whether the asymmetry identified in the HadISST data (Fig. 12) also exists for Z20. Figure 14a shows an El Niño composite of Z20, and Fig. 14b shows a La Niña composite of Z20, constructed using the dataset of White et al. (1999) over the period 1955-99. The same one-standard-deviation outlier criterion that was used previously with SST is also applied here. It can be seen, at least qualitatively, that the patterns for El Niño and La Niña are shifted to the east relative to the patterns identified in the model.

The Z20 patterns for El Niño and La Niña from the data reveal structures that are not mirror opposites of each other in the eastern equatorial Pacific. In the western equatorial Pacific, the data are sufficiently noisy that it is difficult to identify differences between the patterns. Unfortunately, the asymmetry pattern from data (not shown) is noisier still and is not able to identify whether the asymmetry pattern identified in the model is realistic.

The dominant decadal pattern for the thermocline depth variations (Fig. 4) could also provide a means to modulate the strength of the subtropical cells (STCs), which connect the subduction regions in the extratropics with the upwelling regions along the equator. During decades when model ENSO events are strong and mean SSTs in the eastern equatorial Pacific are warm, the mean basin-scale zonal thermocline slope between $5^{\circ} \mathrm{S}$ and $10^{\circ} \mathrm{S}$ would be reduced. This leads to a reduced interior geostrophic inflow toward the equator. Thus an STC weakening of the type described by McPhaden and Zhang (2002) for the 1976/77 shift in the Pacific could follow as a consequence of an increase in ENSO amplitude for the model, rather than being the trigger for the changes in ENSO behavior.

In comparing the ECHO-G model with observations, we have focused primarily on SST. Unfortunately, an explicit comparison of the dominant decadal structure of thermocline depth variability between the model and the data, as we have considered for SST, is very difficult because of the paucity of pre-1980 subsurface measurements. McPhaden and Zhang (2002) have constructed a difference plot of the tropical thermocline depth between the decade following and the decade preceding the 1976/77 shift (their Fig. 3b). The resulting pattern differs from the pattern of thermocline depth variations associated with ENSO in that it is of broader meridional extent and the maximum changes are much less confined to the equatorial waveguide. Thus their analysis lends support to the time-scale separation be- 

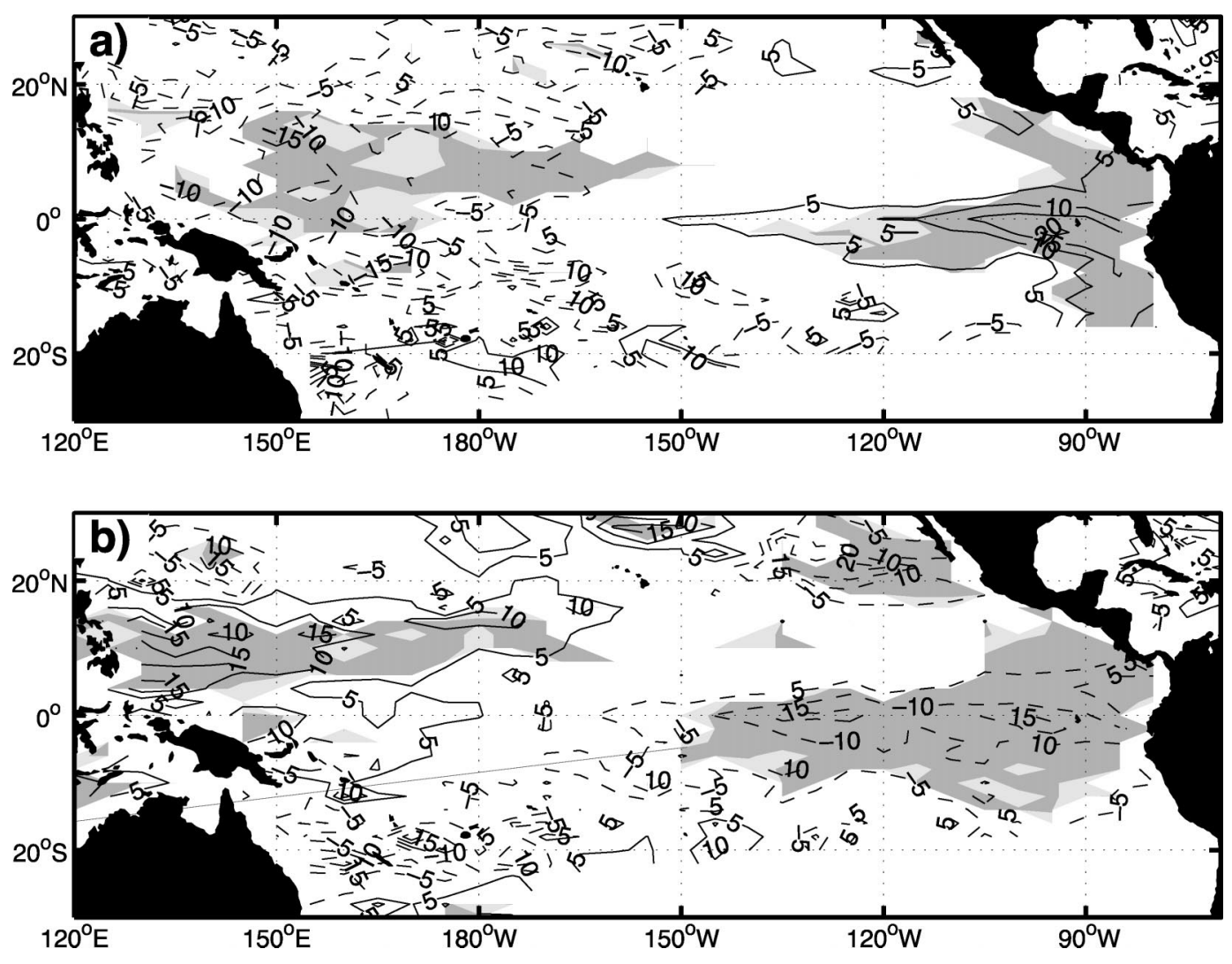

FIG. 14. Composites of the Z20 structure for (a) El Niño and (b) La Niña in the White et al. (1999) dataset from 1955 to 1999 , in units of $\mathrm{m}$. Significance levels of $90 \%$ and $95 \%$ are shown in gray.

tween interannual and decadal Z20 variability found in the ECHO-G model.

\section{Are the results model dependent?}

The question arises as to what extent the results presented here are model dependent. The Zebiak and Cane model simulates the asymmetry between El Niño and La Niña as identified in the HadISST data. For that model, as in ECHO-G, the dominant structure of lowfrequency variability is determined by the ENSO asymmetry (Fig. 1 of Clement et al. 2001). Similar behavior is found for the Center for Ocean-Land-Atmosphere Study (COLA) interactive ensemble anomaly coupled model (Kirtman and Shukla 2002; Yeh and Kirtman 2004, manuscript submitted to J. Climate).

The ENSO asymmetry is also found for the coupled ECHAM4/ocean and isopycnal coordinates, version 3 (OPYC3) simulation analyzed by Timmermann (2003). That study used the same atmosphere model (with T42 rather than T30 resolution) and also used flux corrections. Their model exhibits a high correlation between indices similar to our N3VAR and Z20DEC (their Fig. 6). In addition, the pattern of their second EOF of temperature at 100-m depth (their Fig. 7) is similar to our regression pattern of Z20 shown in Fig. 4. The fact that both ECHAM4/OPYC3 and ECHO-G exhibit similar decadal structures of tropical variability indicates that the modes of variability described for ECHO-G are not a peculiarity of the ocean model.

However, for the latest version of the Max-PlanckInstitut coupled atmosphere-ocean-sea ice model [ECHAM5/Max Planck Institute ocean model, version 1 (MPI-OM1)], which is not flux corrected and which is run with similar ocean model resolution to ECHO-G in the Pacific (but with T42 atmospheric resolution), there is no such separation between the dominant structures of interannual and decadal variability (see Latif et al. 2004 for a description of the coupled model configuration). This is attributed to the fact that there is a cold bias in the mean state of the equatorial Pacific for this model, with the result that the SST (and Z20) patterns characteristic of the model's El Niño and La Niña conditions are very similar. We raise this point as an illustration of how an important relationship may exist in the coupled system between the mean state and the preferred structures of low-frequency variability.

\section{Conclusions}

We have used the 1000-yr integration of the ECHOG model to illustrate how decadal to multidecadal mod- 
ulations of ENSO variability can play an important role in determining the structure and characteristic time scale for TPDV. We have shown that this can result from nonlinearities in ENSO, as the patterns of SST (and Z20) corresponding to the model's characteristic El Niño state are not the mirror opposite of those corresponding to the model's characteristic La Niña state. During periods when ENSO amplitude is large, the asymmetries in SST (and Z20) leave a change in the mean state as a residual, with that change assuming the structure of the asymmetry between the model's El Niño and La Niña states. This ENSO rectifier effect offers a resolution to the counterintuitive problem described in the introductory section, as the changes in the mean state are a consequence rather than the cause of the ENSO amplitude modulations.

Within a linear framework, the terminology "mean state" refers to a stationary basic state about which there are small changes. Within this framework, time scales are separated, and thus the mean state and small changes about it are assumed (to first order) to be independent. The ECHO-G model is characterized by permanently unstable changes between El Niño and La Niña, and thus the anomalies of the model rarely (if ever) assume the perturbation structures shown in Figs. 4 and 5. Thus TPDV in the model should not be understood as a slowly evolving perturbation to a basic mean state, but rather as something that is intrinsically related to nonlinearities in the model.

Our interpretation is distinct from previously proposed theories of TPDV, in that we have specifically identified an aspect of ENSO nonlinearity (i.e., pattern asymmetries) that can account for the dominant structure of TPDV in the model. Furthermore, we have shown that this nonlinearity identified in the model finds support in the observations. The residual SST pattern in the HadISST data, formed by adding the composite El Niño and La Niña patterns, is similar to the results obtained with the ECHO-G model, in that a basin-scale zonal dipole structure exists across the equatorial $\mathrm{Pa}$ cific. Both the model and the data reveal a positive (warm tropical SST perturbation) residual structure in the far eastern equatorial Pacific, which is asymmetric about the equator. In addition, the relative amplitude of the residual for the data (relative to El Niño) is in agreement with the model. This gives us confidence that the asymmetry in the model is not unrealistic. However, as ENSO variability in the model is too strong and too regular, this residual pattern is able to determine by itself the dominant decadal pattern in the model (as revealed by the first decadal EOF in Fig. 2c, which explains $59.6 \%$ of the variance). Other mechanisms that might otherwise influence decadal variability in equatorial SSTs for the model are overwhelmed by the ENSO signal.

We have chosen to emphasize the impact of variability on the mean state, but the question also arises as to what ultimately drives the decadal ENSO amplitude modu- lations. It was mentioned earlier that ENSO behavior for coupled models such as that of Zebiak and Cane, where the mean state is prescribed, show a strong sensitivity to changes in background stratification. At first glance, our analysis of decadal changes in equatorial thermocline stratification for ECHO-G suggests that stratification changes may be acting as a negative feedback for decadal ENSO amplitude modulations, since periods of strong ENSO variability are associated with reduced (time averaged) stratification. In fact, for the ECHO-G model, our work implies that the question itself (of whether low-frequency mean state changes impact ENSO variability) is inherently problematic, given that the mean stratification changes do not represent small decadal perturbations about a stationary basic state, but are rather the result of temporal averaging over the unstable transitions associated with ENSO variability. It is our hope that the results presented here motivate future work in this area.

Acknowledgments. The authors would like to thank Stephanie Legutke, Niklas Schneider, Richard Seager, Gilles Reverdin, Gerrit Burgers, and Axel Timmermann for their constructive input. We would also like to thank Billy Kessler for his numerous suggestions and comments as well as an anonymous reviewer for their comments on the manuscript. This work was supported by the German Ocean CLIVAR program, and the computations were performed at the German Climate Computing Center (DKRZ).

\section{REFERENCES}

Baquero-Bernal, A., M. Latif, and S. Legutke, 2002: On dipolelike variability of sea surface temperature in the tropical Indian Ocean. J. Climate, 15, 1358-1368.

Barnett, T., D. Pierce, M. Latif, D. Dommenget, and R. Saravanan, 1999: Interdecadal interactions between the Tropics and midlatitudes in the Pacific basin. Geophys. Res. Lett., 26, 615-618.

Burgers, G., and D. B. Stephenson, 1999: The normality of El Niño. Geophys. Res. Lett., 26, 1027-1030.

Clement, A. C., M. A. Cane, and R. Seager, 2001: An orbitally driven tropical source for abrupt climate change. J. Climate, 14, 23692375 .

Federov, A., and S. Philander, 2000: Is El Niño changing? Science, 288, 1997-2002.

Frey, H., M. Latif, and T. Stockdale, 1997: The coupled GCM ECHO2. Part I: The tropical Pacific. Mon. Wea. Rev., 125, 703-720.

Graham, N. E., 1994: Decadal-scale climate variability in the tropical and North Pacific during the 1970s and 1980s: Observations and model results. Climate Dyn., 10, 135-162.

Gu, D., and S. Philander, 1995: Secular changes of annual and interannual variability in the Tropics during the past century. $J$. Climate, 8, 864-876.

- , and — 1997: Interdecadal climate fluctuations that depend on exchanges between the Tropics and extratropics. Science, 275, $805-807$.

Hibler, W. D., 1979: A dynamic thermodynamic sea ice model. J. Phys. Oceanogr., 9, 815-846.

Kirtman, B., and P. Schopf, 1998: Decadal variability in ENSO predictability and prediction. J. Climate, 11, 2804-2822.

, and J. Shukla, 2002: Interactive coupled ensemble: A new 
coupling strategy for CGCMs. Geophys. Res. Lett., 29, 1367, doi:10.1029/2002GL014834.

Kleeman, R., J. McCreary, and B. Klinger, 1999: A mechanism for the decadal variation of ENSO. Geophys. Res. Lett., 26, $1743-$ 1746.

Knutson, T. R., S. Manabe, and D. Gu, 1997: Simulated ENSO in a global coupled ocean-atmosphere model: Multidecadal amplitude modulation and $\mathrm{CO}_{2}$ sensitivity. J. Climate, 10, 138-161.

Latif, M., and T. B. Barnett, 1994: Causes of decadal climate variability over the North Pacific and North America. Science, 266, 634-637.

_ , and —_, 1996: Decadal climate variability over the North Pacific and North America: Dynamics and predictability. J. Climate, 9, 2407-2423.

— dicting multidecadal-scale changes in the North Atlantic thermohaline circulation with sea surface temperature. J. Climate, 17, 1605-1614.

Legutke, S., and E. Maier-Reimer, 1999: Climatology of the HOPEG global ocean general circulation model. German Climate Computer Center (DKRZ) Tech. Rep. 21, 90 pp.

— circulation model ECHO-G. German Climate Computer Center (DKRZ) Tech. Rep. 18, 62 pp.

Marsland, S. J., M. Latif, and S. Legutke, 2003: Antarctic circumpolar modes in a coupled ocean-atmosphere model. Ocean Dyn., 53, 323-331.

McCreary, J., and P. Lu, 1994: Interaction between the subtropical and equatorial ocean circulations: The subtropical cell. J. Phys. Oceanogr., 24, 466-497.

McPhaden, J. J., and D. Zhang, 2002: Slowdown of the meridional overturning circulation in the upper Pacific Ocean. Nature, 41, 603-608.

Pacanowski, R. C., and S. G. H. Philander, 1981: Parameterization of vertical mixing in numerical models of tropical oceans. $J$. Phys. Oceanogr., 11, 1443-1451.

Parker, D. E., N. A. Rayner, E. B. Horton, and C. K. Folland, 1999: Development of the Hadley Centre sea ice and sea surface temperature data sets (HadISST). Proc. WMO Workshop on Advances in Marine Climatology-CLIMAR99, Vancouver, BC, Canada, WMO, 194-203.

Rayner, N. A., E. B. Horton, D. E. Parker, C. K. Folland, and R. B. Hackett, 1996: Version 2.2 of the Global Sea-Ice and Sea Surface Temperature data set, 1903-1994. Hadley Centre Climate Research Tech. Note CRTN 74, 25 pp.

Rodgers, K. B., M. Latif, and S. Legutke, 2000: Sensitivity of equa- torial Pacific and Indian Ocean watermasses to the position of the Indonesian Throughflow. Geophys. Res. Lett., 27, 29412944.

Roeckner, E., and Coauthors, 1996: The atmospheric general circulation model ECHAM-4: Model description and simulation of present day climate. Max Planck Institute for Meteorology Tech. Rep. 218, 90 pp.

Schneider, N., A. J. Miller, and D. W. Pierce, 2002: Anatomy of North Pacific decadal variability. J. Climate, 15, 586-605.

Smith, T. M., R. W. Reynolds, R. E. Livezey, and D. C. Stokes, 1996 Reconstruction of historical sea surface temperatures using empirical orthogonal functions. J. Climate, 9, 1403-1420.

Timmermann, A., 2003: Decadal ENSO amplitude modulations: A nonlinear paradigm. Global Planet. Change, 37, 135-156.

__ , and F.-F. Jin, 2002: A nonlinear mechanism for decadal El Niño amplitude changes. Geophys. Res. Lett., 29, 1003, doi:10.1029/ 2001GL013369.

_ J. Oberhuber, A. Bacher, M. Esch, M. Latif, and E. Roeckner, 1999: Increased El Niño frequency in a climate model forced by future greenhouse warming. Nature, 398, 694-697.

_, F.-F. Jin, and J. Abschagen, 2003: A nonlinear theory for El Niño bursting. J. Atmos. Sci., 60, 152-165.

Torrence, C., and P. J. Webster, 1999: Interdecadal changes in the ENSO-monsoon system. J. Climate, 12, 2679-2690.

Trenberth, K. E., and J. W. Hurrell, 1994: Decadal atmosphere-ocean variations in the Pacific. Climate Dyn., 9, 303-319.

Vimont, D. J., D. S. Battisti, and A. C. Hirst, 2002: Pacific interannual and interdecadal equatorial variability in a $1000-y r$ simulation of the CSIRO coupled general circulation model. J. Climate, $\mathbf{1 5}$, $160-178$

White, W., Y. Tourre, and Y. Kushnir, 1999: Evolution of interdecada variability in sea level pressure, sea surface temperature, and upper ocean temperature over the Pacific Ocean. J. Phys. Oceanogr., 29, 1528-1541.

Wolff, J.-O., E. Maier-Reimer, and S. Legutke, 1997: The Hamburg Ocean Primitive Equation Model. German Climate Computer Center (DKRZ) Tech. Rep. 13, 98 pp.

Wyrtki, K., and B. Kilonsky, 1984: Mean water and current structure during the Hawaii-to-Tahiti shuttle experiment. J. Phys. Ocean ogr., 14, 242-254.

Zebiak, S. E., and M. A. Cane, 1991: Natural climate variability in a coupled model. Workshop on Greenhouse-Gas-Induced Climate Change: A Critical Appraisal of Simulations and Observations, M. E. Schlesinger, Ed., Elsevier, 457-470.

Zhang, Y., J. Wallace, and D. Battisti, 1997: ENSO-like interdecadal variability: 1900-1993. J. Climate, 10, 1004-1020. 